\title{
The Xenopus ribosomal gene enhancers bind an essential polymerase I transcription factor, $\mathrm{xUBF}$
}

\author{
Craig S. Pikaard, Brian McStay, Michael C. Schultz, Stephen P. Bell, ${ }^{1}$ and Ronald H. Reeder \\ Basic Sciences Division, Hutchinson Cancer Research Center, Seattle, Washington 98104 USA; ${ }^{1}$ Howard Hughes Medical \\ Institute, Department of Biochemistry, University of California, Berkeley, California 94720 USA
}

\begin{abstract}
We purified xUBF on the basis of its ability to specifically bind the enhancer elements of the Xenopus laevis rRNA genes. XUBF also binds to both upstream and downstream regions of the $X$. laevis ribosomal gene promoter and is essential for polymerase I transcription. Unexpectedly, xUBF binds to both upstream and downstream regions of the human ribosomal gene promoter, producing footprints that are indistinguishable from the footprints produced by hUBF, a previously described polymerase I transcription factor isolated from human cells. Despite extensive sequence divergence of vertebrate polymerase I promoters, these data suggest an evolutionary conservation of the primary DNA-protein interaction.
\end{abstract}

[Key Words: Xenopus; rDNA; enhancer; transcription factor; RNA polymerase I]

Received July 19, 1989; revised version accepted August 23, 1989.

The rRNA genes of Xenopus laevis contain repetitive elements within the intergenic spacer that act as orientation- and position-independent enhancers of transcription from both the gene and spacer promoters (Busby and Reeder 1983; Moss 1983; Labhart and Reeder 1984; DeWinter and Moss 1987; Pikaard and Reeder 1988; for a diagram of the intergenic spacer region, see Fig. 1). The essential core of each enhancer has been identified as a sequence of $\sim 56 \mathrm{bp}$ (Pikaard and Reeder 1988), $32 \mathrm{bp}$ of which have significant homology with an essential region of the gene promoter (a match of 25 out of 32, with the promoter region from -83 to -114 ). In addition, it has been observed in oocyte injection experiments that transcription from a cloned ribosomal gene promoter can be abolished by coinjection of a plasmid carrying a block of enhancers (Labhart and Reeder 1984). From these results we have previously hypothesized that the enhancers bind an essential transcription factor that also binds to the promoter.

In this paper we used DNase I footprinting as an assay to monitor the purification of an enhancer-binding protein called xUBF. As predicted, $\mathrm{xUBF}$ also binds to the enhancer homology region within the promoter and is an essential transcription factor for the $X$. laevis ribosomal genes. xUBF also binds to other sites, including the region surrounding the $\mathrm{T} 3$ terminator /a 7-nucleotide box from -200 to -194 , which is essential for termination; Labhart and Reeder 1987) and the region of the promoter surrounding the site of transcription initiation.

Conserved DNA sequence elements are present in promoters recognized by RNA polymerases II and III in various organisms, but no extensive sequence conserva- tion has been noted previously between polymerase I promoters of different species. This observation has been ascribed to the fact that RNA polymerase I is only known to recognize the promoters of ribosomal genes. Such a one-gene/one-polymerase system is presumably free to evolve more rapidly than transcription systems for polymerase II or III genes. In keeping with this hypothesis, transcription by RNA polymerase $I$ is relatively species specific and, in general, extracts made from one species are unable to recognize the promoters from other species (Grummt et al. 1982; Learned and Tjian 1982; Mishima et al. 1982; Miesfeld and Arnheim 1984). However, it is possible to relax this species specificity in vitro. For example, by altering the ionic conditions, a mouse extract can be made to recognize a frog promoter and to initiate transcription at a low level (Wilkinson and Sollner-Webb 1982). This suggests that the factors essential for polymerase I transcription have been conserved to some degree.

In this paper we show that despite the extensive sequence divergence of polymerase I promoters, a frog transcription factor, $\mathrm{xUBF}$, produces distinct footprints on the human ribosomal gene promoter that are identical with the footprints of hUBF, a human polymerase I transcription factor (hUBF was formerly called UBFl; Bell et al. 1988). In addition, hUBF produces footprints on the $X$. laevis enhancer elements that are identical to those produced by $x U B F$. The similarity in the DNA binding characteristics of these two proteins suggests that the underlying structure of vertebrate RNA polymerase I promoters have been conserved. These results also strengthen the likelihood that polymerase I en- 


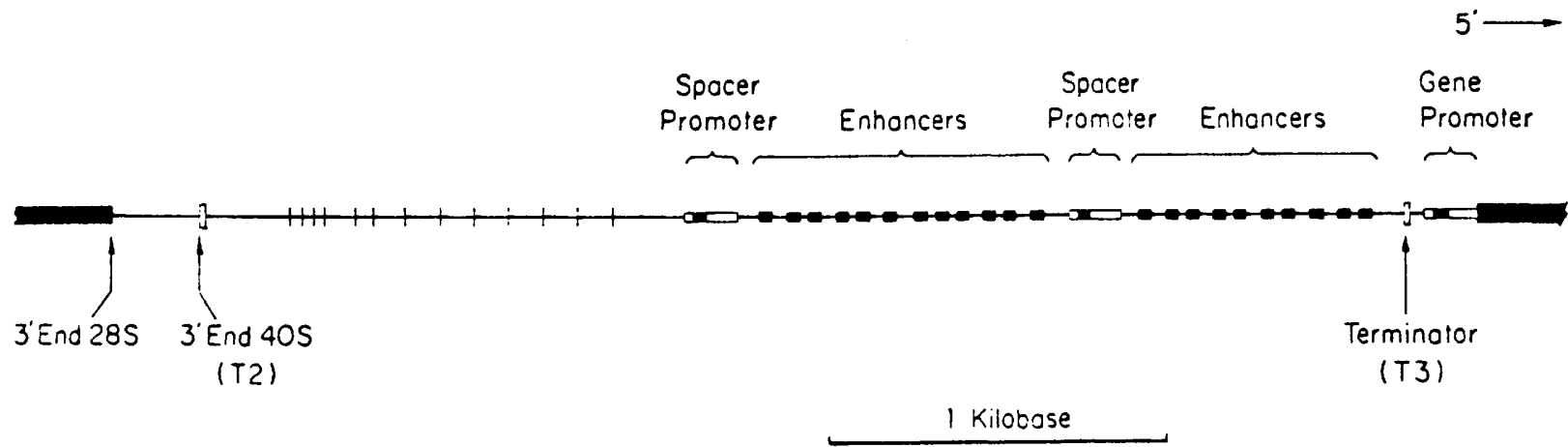

Figure 1. Diagram of the intergenic spacer region from a repeating unit of $X$. laevis ribosomal DNA that contains two spacer promoters. Other regulatory elements that are indicated are the gene promoter, enhancer elements $(60-$ or 81 -bp repeats $)$, and two sites of $3^{\prime}$-end formation (T2 and T3). Small black boxes indicate homologous regions between the enhancer elements and the promoters.

hancer elements are also present in mammalian ribosomal DNA.

\section{Results}

\section{Purification of $x U B F$ by affinity chromatography}

Using an end-labeled enhancer DNA probe, we were able to detect footprinting activity in crude nuclear extracts of cultured Xenopus kidney cells (an example of such a footprint is shown in Fig. 3A). With this footprinting activity as a guide, we devised the purification scheme shown in Figure 2A. The scheme includes step elution from DEAE-Sepharose and Bio-Rex-70, followed by several rounds of DNA affinity chromatography (Kadonaga and Tjian 1986) on a column containing enhancer sequences. A silver-stained gel of protein samples from each step in the purification scheme is shown in
Figure 2B. Two polypeptides, of 82 and $85 \mathrm{kD}$ apparent mass, are consistently enriched by this procedure (Fig. 2B, lane 4). Similar proteolytic fragments were produced by partial cyanogen bromide $(\mathrm{CNBr})$ cleavage of the 82 and $85-\mathrm{kD}$ bands that had been separated by gel electrophoresis (C.S. Pikaard, unpubl.). This suggests that the two polypeptides are closely related, and we refer to them collectively as xUBF. We estimate that XUBF has been purified $\sim 8000$-fold on the basis of footprinting activity per microgram of protein and is present in cultured kidney cells at $\sim 75,000$ molecules per cell.

The footprint over the enhancer sequences (Fig. $3 \mathrm{~A}$ ) is extensive, covering essentially all of each 60 - and 81 -bp element, and does not change throughout the purification scheme (data not shown). Making the conservative assumption that only one protein molecule binds to each enhancer element, and on the further assumption that all of the protein in the affinity-purified material is
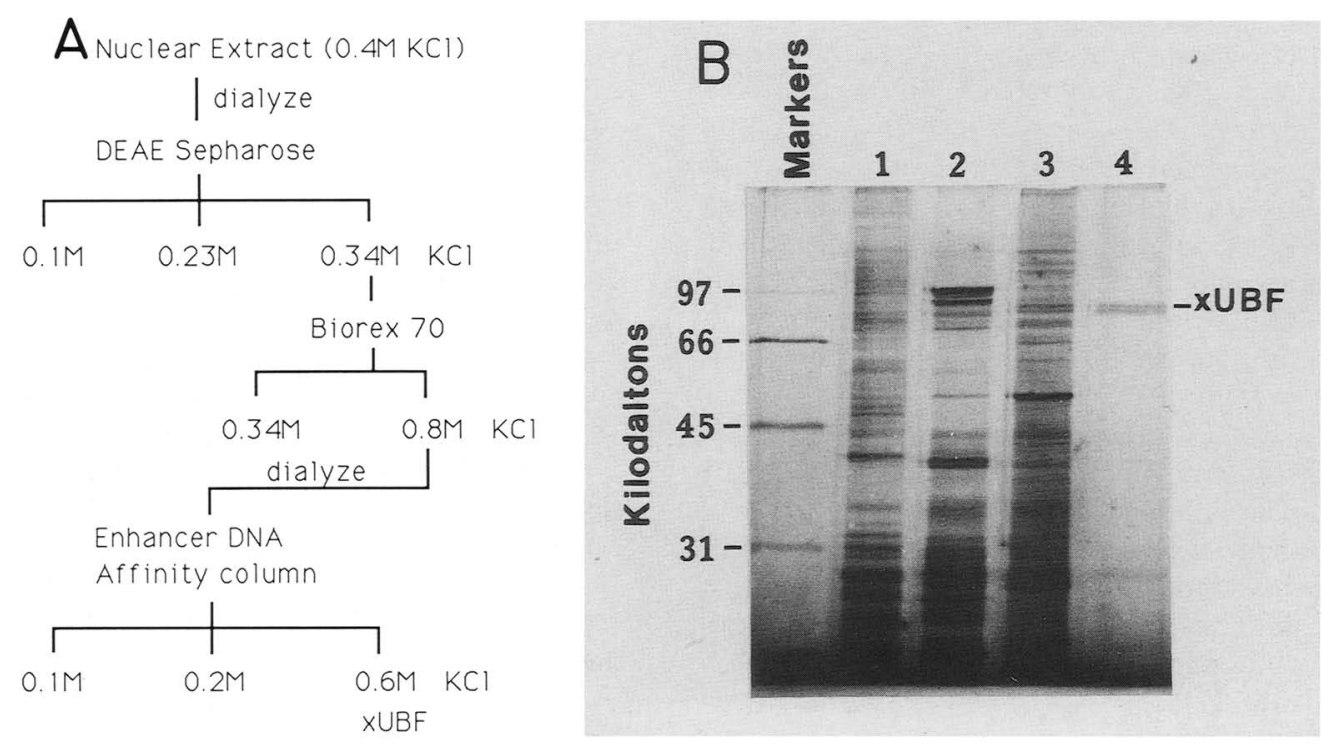

Figure 2. $(A)$ Scheme for purification of $x U B F .(B)$ Silver-stained SDS-acrylamide gel of various stages in the purification of $x U B F$. (Lane 1) Nuclear extract; (lane 2) DEAE-Sepharose $0.34 \mathrm{M} \mathrm{KCl}$ eluate; (lane 3) Bio-Rex-70 0.8 $\mathrm{M} \mathrm{KCl}$ eluate; (lane 4) second round DNA affinity column, $0.6 \mathrm{M} \mathrm{KCl}$ eluate. xUBF typically electrophoreses as two bands, 82 and $85 \mathrm{kD}$ apparent mass. xUBF from this purification was used in all of the experiments presented in this paper except that experiment shown in Fig. 5. 


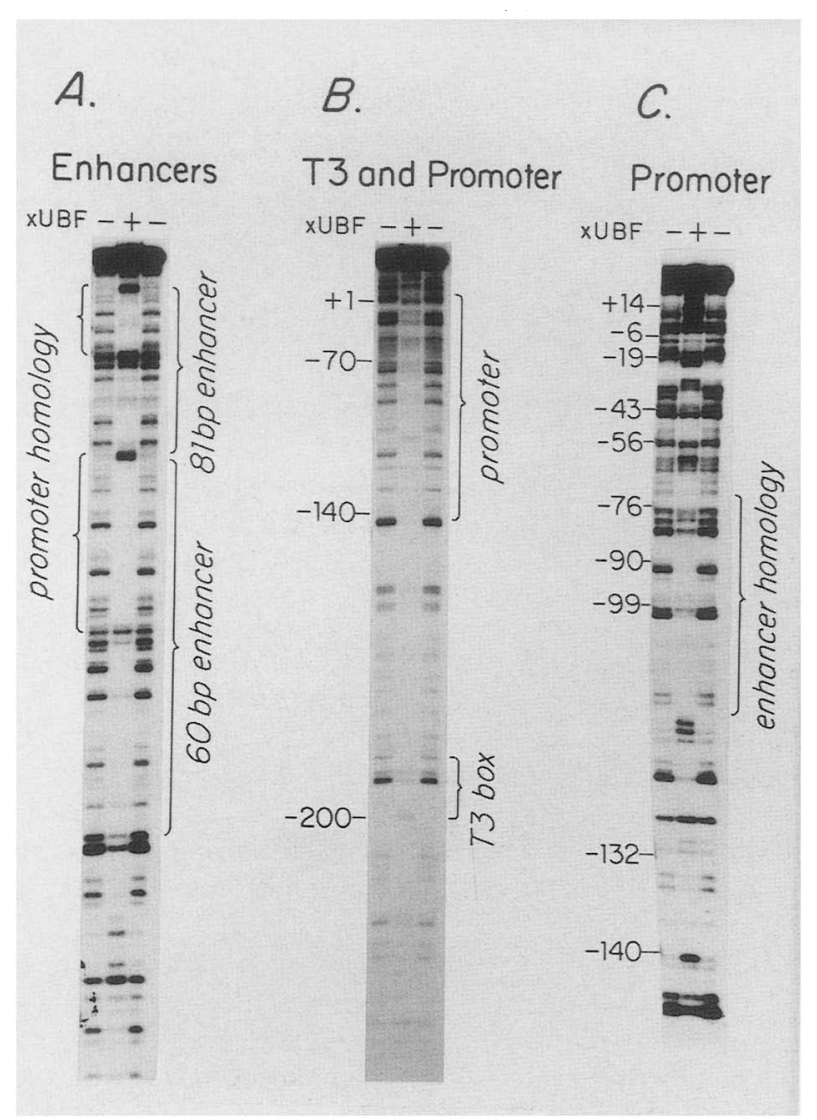

Figure 3. DNase I footprinting of affinity-purified $x U B F$ on various regions of the intergenic spacer. $(A)$ The footprinting probe was an end-labeled DNA fragment containing a 60- and an 81-bp enhancer element in tandem labeled on the coding strand; $(B)$ probe labeled at -245 (relative to transcription initiation) on the noncoding strand; $(C)$ probe labeled at -167 on the noncoding strand. (middle lanes) About $20 \mathrm{ng}$ of affinity-purified xUBF was incubated with $1 \mathrm{ng}$ of probe before addition of DNase I.

active, we calculate that we obtain complete footprints at a protein-DNA molar ratio of no more than $3.4: 1$ l 5 ng of xUBF will completely footprint $1 \mathrm{ng}$ of a 200-bp probe that has two enhancer elements and therefore has at least two binding sites).

\section{$\mathrm{x} U B F$ binds to other sites within the intergenic spacer}

At each step in the purification of $\mathrm{xUBF}$, fractions that footprint over the enhancers also footprint around the T3 terminator and over the initiation region of the promoter. All of these footprinting activities remain in the most highly purified preparations. Examples of such footprints are shown in Figure 3. In this experiment, affinity-purified $\mathrm{xUBF}$ (same preparation whose protein gel is shown in Fig. 2B, lane 4) was footprinted on three different end-labeled probes. This allowed us to survey all possible binding sites from the enhancers (upstream of -245 ) downstream to the region of transcription initiation around +1 . Figure $3 \mathrm{~A}$ shows typical footprinting over the enhancers. Figure 3B shows clear protection upstream of the T3 box, a strong hypersensitive site at -200 on the upstream edge of the box, and extensive protection of the GC-rich region between the $\mathrm{T} 3$ box and the promoter. Figure $3 \mathrm{C}$ focuses on the gene promoter and shows a small protection over the upstream region $(-140$ to -130$)$ and extensive protections over the enhancer homology region and the region surrounding the site of transcription initiation at +1 (footprinting around the initiation site is better seen on the probes used in Figs. 4B and 5).

We were reluctant to conclude that $x U B F$ could be binding to all of these different regions, but the following arguments indicate that such is the case. First, footprinting on all of these sites occurs over no more than a fivefold range of protein-DNA ratio, indicating that none of the footprints is due to a minor contaminant (a titration experiment on the promoter is shown in Fig. 5, lanes 1-5). Second, all of the footprints are abolished by the same amount of competing enhancer oligonucleotide (data not shown).

The most direct argument that all of the footprints are produced by the same protein comes from renaturing the $x U B F$ bands from an SDS-acrylamide gel. Figure 4A shows another preparation of $x U B F$ independent from the preparation shown in Figure 2B. Approximately $1 \mu \mathrm{g}$ of affinity-purified material from this preparation was electrophoresed in one lane of an SDS-acrylamide gel. After cutting the lane into five slices, the protein from each slice was eluted, renatured, and tested for footprinting activity. As shown in Figure 4B, footprinting activity was recovered only from the slice containing the $82-$ and $85-\mathrm{kD}$ xUBF bands. This renatured protein footprinted over the enhancers, around T3, and over both upstream and downstream regions of the promoter. From the renaturation experiment, we conclude that one or both of the two bands called xUBF are responsible for all of these footprints.

\section{The promoter has at least two independent binding regions for $X U B F$}

DNase I footprinting of $\mathrm{xUBF}$ on the gene promoter (Figs. 3C and 5) shows extensive protections over the enhancer homology region, as well as over the region surrounding the site of transcription initiation at +1 . This suggests at least two binding regions on the promoter. To explore the binding of XUBF to these regions, we performed the titration experiment shown in Figure 5, lanes $1-5$. With the lowest amount of affinity-purified xUBF in the titration $(10 \mathrm{ng})$, first we observe protection over the enhancer homology region (lane 1), indicating that xUBF may have its highest affinity for this part of the promoter. As the amount of $x U B F$ in the binding reaction is increased, the footprint over the enhancer homology region becomes more extensive, as does the footprint surrounding the initiation site (lane 2). With additional xUBF, it becomes difficult to obtain efficient DNase digestion, and it appears that, eventually, the whole probe is protected to some extent (lanes 3 and 4). 


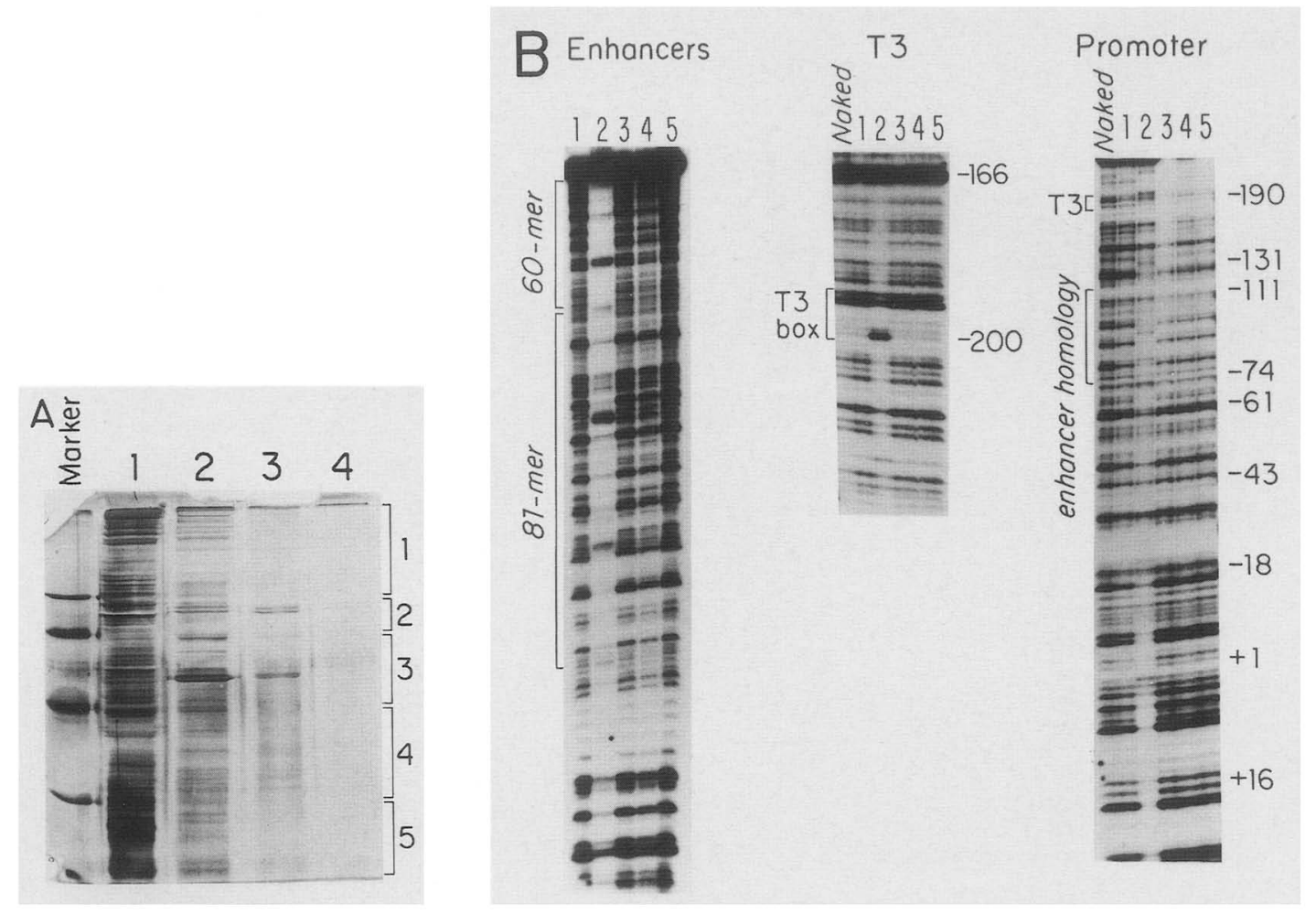

Figure 4. DNase I footprinting of xUBF after renaturation from an SDS-acrylamide gel. $(A)$ Silver-stained SDS-acrylamide gel of various steps in the purification of $x U B F$ (a purification independent of the one shown in Fig. 2). (Lane 1) Whole nuclear extract; (lane 2) $0.8 \mathrm{M} \mathrm{KCl} \mathrm{Bio-Rex-70} \mathrm{eluate;} \mathrm{(lane} \mathrm{3)} \mathrm{first} \mathrm{round} \mathrm{of} \mathrm{DNA} \mathrm{affinity} \mathrm{chromatography;} \mathrm{(lane} \mathrm{4)} \mathrm{second} \mathrm{round} \mathrm{affinity} \mathrm{chromatography.}$ About $1 \mu \mathrm{g}$ of the material applied to lane 4 was electrophoresed on a preparative gel, which was then cut into five slices /using prestained molecular weight markers as a guidel, as indicated. The protein from each slice was eluted, renatured, and used for the DNase I footprinting shown in $B$. The bands visible in slice 3 of lane 4 and extending across the gel have since been identified as contaminating finger keratins caused by handling the glass gel plates without gloves. $(B)$ DNase I footprinting of proteins eluted from the five preparative gel slices described in $A$. (Enhancers) Same enhancer probe used in Fig. 3 ; (T3) probe labeled at -245 , relative to the site of transcription initiation on the noncoding strand; (promoter) probe labeled at +50 on the coding strand. Note that footprinting is only recovered from slice 2 , which contains the XUBF bands.

Thus, xUBF binding is fairly selective at lower proteinDNA ratios but becomes less selective at higher protein inputs.

To further define essential sequences for $\mathrm{xUBF}$ binding, we performed footprinting on 15 linker scanner (LS) mutants of the promoter, some of which are shown in Figure 5, lanes 6-20 [the effect of these mutants on promoter activity has been described in Reeder et al. (1987) and is summarized at the bottom of Fig. 5]. We found mutants that impaired binding to either the enhancer homology region or to the initiation region but not to both simultaneously. This indicates that binding to each region occurs independently. For example, a mutation within the enhancer homology region (LS - 96) -87 ) decreases promoter activity about fivefold in oocyte injection experiments and severely disrupts xUBF footprinting in the upstream domain. However, LS $-96 /-87$ has no effect on footprinting around the initiation site (Fig. 5, lane 10). Conversely, LS $-7 /+3$ impairs footprinting near the initiation site and essentially abolishes transcriptional activity of the promoter, but has no effect on footprinting over the enhancer homology (Fig. 5, lane 19). Likewise, LS $-17 /-8$ eliminates a hypersensi- tive site at -20 but again has no effect on footprinting over the rest of the promoter. LS $-83 /-75$ is the only mutation within the promoter that is either neutral or sometimes stimulates transcription. LS $-83 /-75$ is also the only mutation of the enhancer homology region that does not impair, and perhaps improves, footprinting binding to this region of the promoter (Fig. 5, lane 13).

Analysis of footprinting on LS mutants also suggests that XUBF binding involves more than one localized DNA recognition sequence. For instance, the footprint over the enhancer homology region of LS $-111 /-102$ is reduced to about two-thirds its original extent (Fig. 5, lane 7) but is not completely abolished. This suggests that the mutation has eliminated a binding site, but other binding sites are still available for $\mathrm{xUBF}$ in this region of the promoter.

Although we have only shown selected examples, there is a positive correlation between the effect of each mutation on transcription and its effect on xUBF binding for all 15 LS mutants. This is consistent with xUBF binding to the promoter being required for transcription. However, we also note that xUBF binds to additional regions that have no known function in tran- 


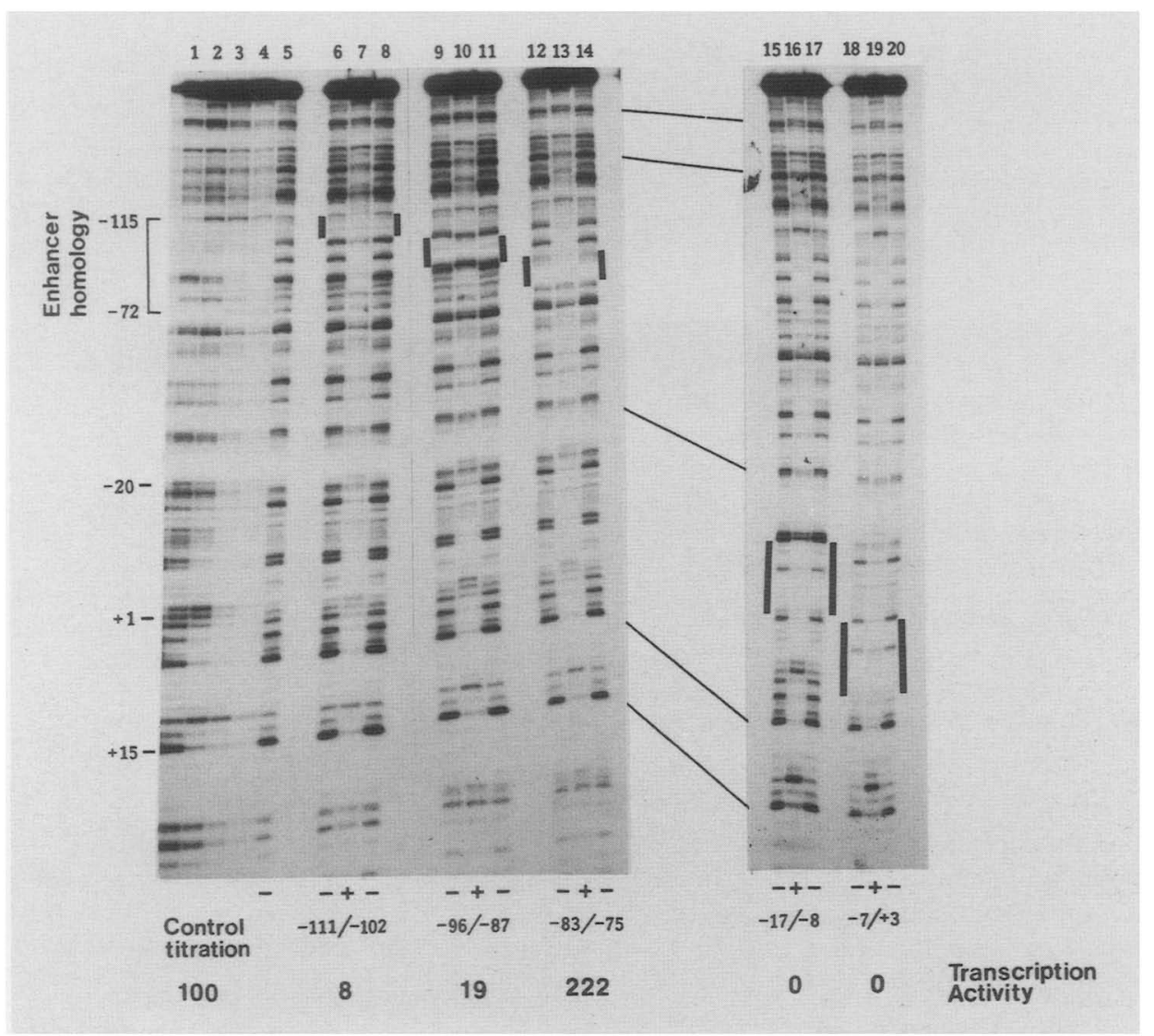

Figure 5. Titration of $x U B F$ binding and footprinting on various promoter mutants. The DNA probes were all end-labeled at +50 on the coding strand (same probe used in Fig. 4B). (Lanes 1-5) A titration in which either 10, 25, 50, 75, or 0 ng of affinity-purified xUBF was incubated with $1 \mathrm{ng}$ of probe (wild-type promoter sequence) prior to DNase I digestion. (Lanes 6-20) Various linker scanner mutants of the promoter were tested for footprinting. Lanes $7,10,13,16$, and 19 received $50 \mathrm{ng}$ of $\mathrm{xUBF}$, whereas the other lanes received none. (Lanes 6-8) LS-111/-102; (lanes 9-11) LS-96/-87; (lanes 12-14) L-83/-75; (lanes 15-17) LS-17/-8; (lanes 18-20) LS $-7 /+3$. Vertical bars indicate the locations of each cluster of point mutations in the LS mutants. The relative transcriptional activity of each mutant promoter (oocyte injection assay) is summarized at bottom (data from Reeder et al. 1987).

scription. The most obvious example is the footprinting seen over the GC-rich region between the T3 box and the promoter (Fig. 3B).

\section{$x U B F$ is a ribosomal gene transcription factor}

We noted previously that enhancer sequences injected into an oocyte nucleus will diminish transcription from a ribosomal gene promoter coinjected on a separate plasmid (Labhart and Reeder 1984). We interpreted this result to mean that the enhancers bind a transcription factor essential for promoter function. This result can be reproduced in vitro, using an S-100 transcription extract made from cultured $X$. laevis kidney cells (Fig. 6). Figure $6 \mathrm{~A}$ shows that as increasing amounts of enhancer sequences are added to the extract, the level of transcription from a promoter added on a separate plasmid is progressively reduced to zero. Figure $6 \mathrm{~B}$ shows a similar experiment in which addition of $x U B F(\sim 30 \mathrm{ng})$ to the reactions overcomes the enhancer competition (Fig. 6B, lanes 4, 6, and 8), though not to control levels (cf. Fig. 6B, lanes 1 and 2) with this amount of xUBF. The most dra- matic effect is with high amounts of competing enhancers, where xUBF rescues transcription from zero levels (lanes 7 and 8). Figure 6B, lane 2, shows that adding $\mathrm{XUBF}$ to the reaction in the absence of enhancer competition has little effect, presumably because xUBF is already saturating in the reaction. These results suggest that $\mathrm{xUBF}$ is a transcription factor that interacts specifically with both the enhancers and the promoter.

The transcription factor activity of xUBF can also be demonstrated in a different type of in vitro transcription assay. Recently we developed a method for isolating oocyte nuclei under oil so that the nuclear contents remain as concentrated as they were in the living cell. Figure 7, lane 1 , shows that adding a ribosomal gene promoter and nucleotide triphosphates to homogenates of such nuclei results in transcription. Details of the reaction will be published elsewhere (M. Schultz, in prep.). However, in this paper we report one result that is relevant to xUBF. When the nuclear homogenate is centrifuged at moderate speed $(10,500 \mathrm{~g})$, almost all transcription activity is lost (Fig. 7, lanes 2 and 3). Remixing the supernatant and pellet together restores the initial activity (lane 4), sug- 
Figure 6. $x U B F$ can overcome enhancer competition of transcription in vitro. $(A)$ Enhancer elements specifically compete for an essential transcription factor. (Lane 1) An in vitro transcription reaction received $20 \mathrm{ng}$ of a plasmid containing a ribosomal gene promoter plus $400 \mathrm{ng}$ of pGEM3 vector DNA as nonspecific competitor. (Lane 2) The competitor was $400 \mathrm{ng}$ of a pGEM3 plasmid with an insert of 10 enhancer elements. (Lane 3) The competitor was $400 \mathrm{ng}$ of pGEM3 with an insert of 20 enhancer elements. (Lane 4) The insert was 40 enhancer elements. (Lane 5) The insert was 80 enhancer elements. Note that the total DNA amount is constant in each reaction. $(B)$ Enhancer competition can be rescued by purified xUBF. For each reaction, S-100 extract was preincubated with $200 \mathrm{ng}$ pBR322 as a

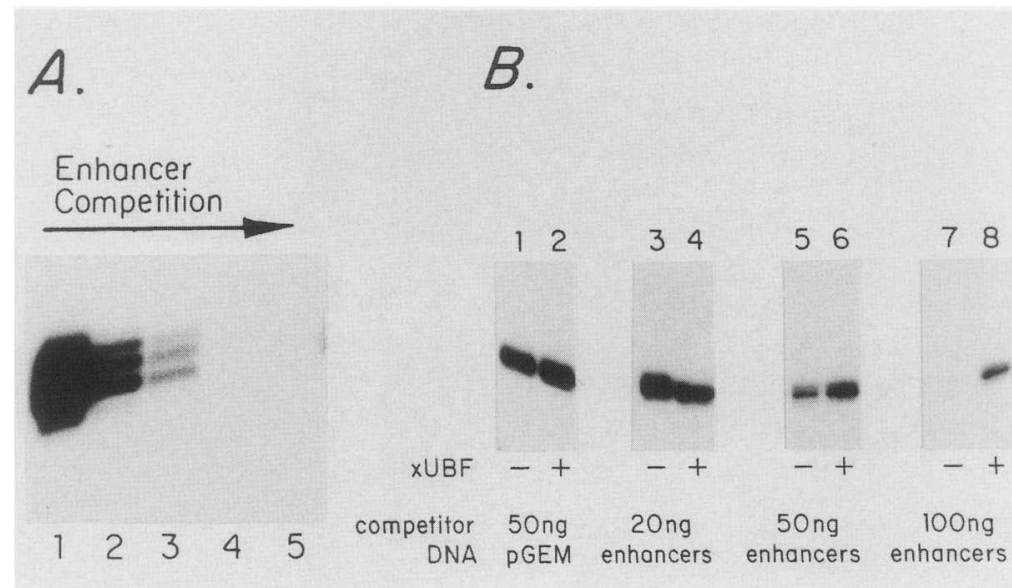
nonspecific competitor prior to the addition of the reaction mix, xUBF or buffer, $100 \mathrm{ng}$ of rDNA template, and a second dose of competitor DNA. (Lane 1) Transcription signal ( $\mathrm{S} 1$ nuclease protection assay) from the control reaction containing $50 \mathrm{ng}$ of pGEM3 DNA as the second competitor. (Lane 2) Addition of $30 \mathrm{ng}$ of xUBF has no effect. (Lanes 3-8) Increasing amounts of a plasmid containing 80 enhancers (pXlr14FA-8) was added as the second competitor DNA. Addition of enhancers depresses transcription (lanes 3,5 , and 7); addition of $30 \mathrm{ng} \times \mathrm{XUBF}$ rescues enhancer competition (lanes 4, 6, and 8).

gesting that some component essential for transcription sediments to the pellet under these conditions. The rapidly sedimenting component is unlikely to be RNA polymerase I, as $>95 \%$ of the polymerase I activity (assayed with nicked calf thymus DNA/ remains in the supernatant. Our working hypothesis is that the rapidly sedimenting component includes XUBF, because by supplementing the inactive supernatant with affinity-purified xUBF nearly full transcription activity is restored (Fig. 7, lane 5).

Addition of affinity-purified xUBF (preparations that had activity in the S-100 extract and nuclear homogenate assays) to partially purified RNA polymerase I (also isolated from cultured kidney cells) does not stimulate the low level of specific initiation activity present in our polymerase preparations (data not shown). Therefore, we suspect that at least one other transcription factor is needed for specific initiation, in addition to polymerase I and $\mathrm{xUBF}$.

\section{$x U B F$ also binds to the human ribosomal gene promoter}

We noticed that several reported characteristics of hUBF, a purified human ribosomal gene transcription factor (Bell et al. 1988), are similar to the characteristics

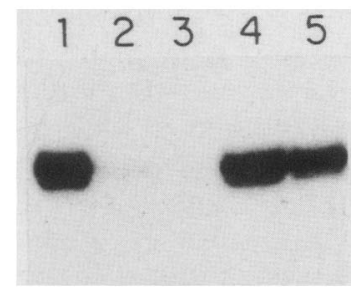

Figure 7. Transcription activity of xUBF in an oocyte nuclear extract. In all lanes, $2.5 \mathrm{ng}$ of template was included in an $8-\mu \mathrm{l}$ reaction. (Lane 1) Whole extract; (lane 2) 10,500g supernatant; (lane 3) 10,500g pellet; (lane 4) pellet and supernatant recombined; (lane 5) supernatant supplemented with $30 \mathrm{ng}$ of xUBF. of $x U B F$. Among these similarities is the fact that purified hUBF electrophoreses as two closely spaced bands on an SDS-acrylamide gel (hUBF runs at 94 and $97 \mathrm{kD}$, whereas $\mathrm{xUBF}$ runs at 82 and $85 \mathrm{kD}$; see also Bell et al. 1989). Preliminary footprints of xUBF on a human promoter probe looked very similar to the published footprints using hUBF. When compared side by side, xUBF and hUBF give virtually identical footprints on the $X$. laevis enhancers and the human promoter (Fig. 8), as well as on the $X$. laevis promoter. This suggests that the DNA recognition properties of the two proteins are similar. hUBF footprints the region of the human promoter between -114 and -75 and induces enhanced DNA cleavages at -20 (Bell et al. 1988) and +20 (C.S. Pikaard, unpubl.). It is interesting that these coordinates for hUBF binding on the human promoter are virtually identical to the domains of the Xenopus promoter footprinted by $x U B F(-114$ to -70 and -20 to $\sim+20$, Fig. 5). This suggests that UBF-binding sites are important determinants of RNA polymerase I promoter architecture. We conclude that xUBF and hUBF are closely related proteins that probably perform the same functions in their respective species.

Previous comparisons of frog and human promoters have failed to indicate any significant conservation of sequence. Thus, the ability of xUBF and hUBF to produce identical footprints was unexpected. The implication is that the underlying structure of polymerase I promoters among vertebrates has been highly conserved such that homologous transcription factors from different species can still bind with precision.

\section{Discussion}

Xenopus enhancers bind an essential transcription factor conserved in evolution

In this paper we have described the purification and characterization of $x U B F$, a transcription factor that spe- 


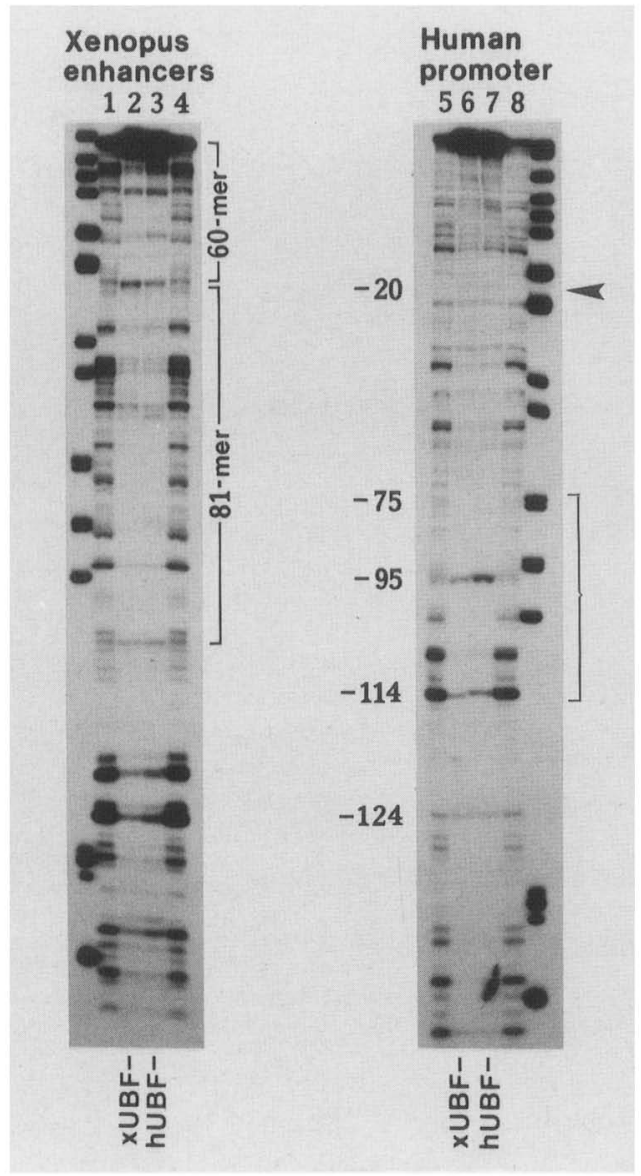

Figure 8. $x U B F$ and hUBF produce identical footprints. (Lanes $1-4$ ) Footprinting on the $X$. laevis enhancer (1 ng of the same probe as in Fig. 3). (Lane 2) $5 \mathrm{ng}$ of $\mathrm{xUBF}$; (lane 3), $5 \mathrm{ng}$ of hUBF. (Lanes 5-8) Footprinting on the human ribosomal gene promoter (1 $\mathrm{ng}$ of probe labeled at -170 on the noncoding strand). (Lane 6) $5 \mathrm{ng}$ of $\mathrm{xUBF}$; (lane 7) $5 \mathrm{ng}$ of hUBF. Outer lanes for each probe show the DNase digestion patterns for the naked DNA. The arrowhead denotes the position of a characteristic enhanced cleavage site at -20 on the human promoter, and the strong footprint from -75 to -115 in the upstream control element (UCE) is bracketed.

cifically interacts with both ribosomal gene enhancers and the promoter. Though enhancers of ribosomal gene transcription have only been documented in Xenopus, it is interesting that the enhancers are not binding a factor unique to frogs. Instead, we have presented evidence that $\mathrm{xUBF}$ is the homolog of the human RNA polymerase I transcription factor hUBF. These proteins produce indistinguishable footprints on the Xenopus enhancers and human promoter (Fig. 8) and on the Xenopus promoter (Bell et al. 1989), indicating that their DNA recognition properties are very similar. This was an unexpected result because the ribosomal gene promoters of humans and frogs do not share obvious sequence homology. The species specificity of ribosomal gene transcription has been thought to be caused by the rapid divergence of promoter sequences concomitant with compensatory changes in the transcription machinery. However, our results suggest that the DNA- binding specificity of UBF has not changed significantly throughout evolution. This suggests that the RNA polymerase I transcription machinery in different species is fundamentally similar, at least in vertebrates. This was also suggested by the observed low-level transcription of a Xenopus rDNA promoter in a mouse extract (Wilkinson and Sollner-Webb 1982). Therefore, it seems likely that species specificity is caused at some other level than UBF binding to the gene promoter. Subtle changes in the spacing of transcription factor-binding sites or in the interaction of UBF with other factors are possibly the causes of species specificity (Bell et al. 1989).

\section{Does $x U B F$ recognize a consensus binding sequence?}

$\mathrm{xUBF}$ binds to the $X$. laevis enhancers around $\mathrm{T} 3$, to both upstream and downstream regions of the promoter, and to the human promoter. In Figure 9 we compare the sequences of the various binding regions and show that a weak consensus element (PyGGGC/ $/ \mathrm{G} / \mathrm{CG}$ ) is present in many of them. This consensus incorporates the TGGGCCG motif proposed by Bell et al. (1988) to be part of the binding site for hUBF on the human promoter.

Even this weak consensus does not fit all cases, however. For example, the consensus element is altered in the LS $-17 /-8$ mutant but affects the footprint only in the loss of hypersensitive sites around -20 . In addition, the consensus motif is not altered in LS $-7 /+3$, a mutation that does impair footprinting (Fig. 5).

xUBF binds preferentially to GC-rich regions, as evidenced by the fact that its binding is nearly immune to poly[d(A-T)] but is highly sensitive to competition by poly $[\mathrm{d}(\mathrm{I}-\mathrm{C})]$. A preference for GC binding is also consistent with the protection seen over the nearly pure GC region between $\mathrm{T} 3$ and the promoter (Fig. 3B).

The difficulty in defining a consensus binding site for XUBF could have several explanations. For example, xUBF may not have a single consensus binding site. The lack of a single binding site consensus sequence has been shown for several DNA-binding proteins, a rigorously documented example being HAPI binding to different sequences within the upstream activating sequence (UAS) regions of the yeast $C Y C 1$ and $C Y C 7$ genes (Pfeifer et al. 1987). It is also possible that xUBF normally interacts with an additional transcription factor that increases the specificity of DNA binding. For example, in human cells, hUBF is known to interact with a second factor, SL1, and the footprint of the interacting pair is different from that of hUBF alone (Bell et al. 1988). Further research is necessary to understand how the relatively relaxed binding specificity of purified $\mathrm{xUBF}$ contributes to the highly specific promoter recognition exhibited by RNA polymerase I.

\section{The role of $\mathrm{x} U B F$ in ribosomal gene enhancer action}

The enhancer elements in the intergenic spacer of $X$. laevis are not sites of transcription initiation but, instead, appear to increase the probability that adjacent 
Pikaard et al.

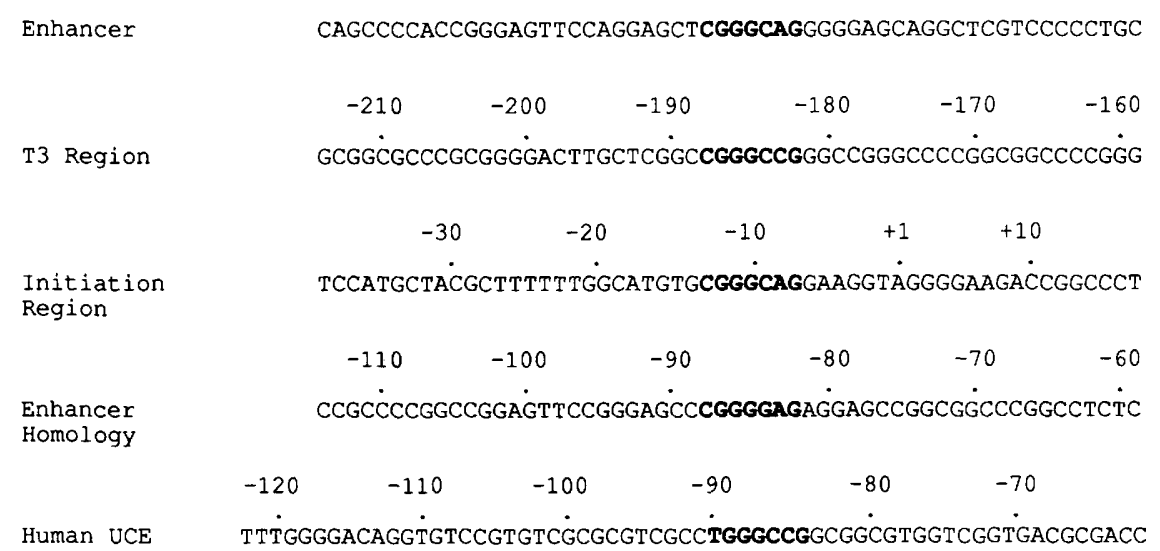

Concensus

PyGGGC/GA/CG

Figure 9. Comparison of DNA sequences in various xUBF-binding regions. The nucleotides in boldface type represent the best match to a potential consensus sequence (bottom).

promoters will initiate transcription. A variety of oocyte injection experiments have led to the conclusion that enhancers compete for the binding of an essential transcription factor that is limiting. Larger blocks of enhancers are more successful in attracting this factor, presumably by virtue of being larger targets for its binding, and are somehow able to then transmit the factor to adjacent promoters (for review, see Reeder 1984). xUBF has the characteristics of this predicted factor in that it binds to the enhancers and to the promoter and acts as a transcription factor. However, we have not ruled out the possibility that other factors associate with $\mathrm{xUBF}$ to mediate full enhancer function.

Are there ribosomal gene enhancer elements in species other than Xenopus?

At this time, polymerase I enhancers of the repetitive Xenopus type have only been shown directly to exist in the two related species, $X$. laevis and $X$. borealis. Do they exist in other organisms or are they a peculiarity of amphibians? The only other direct evidence is a recent report that repetitive elements in the intergenic spacer of Drosophila melanogaster stimulate transcription from adjacent promoters in proportion to their copy number (Grimaldi and Di Nocera 1988). Thus, these elements, in a species from a different phylum, have some of the functional characteristics of the Xenopus enhancers.

An indirect argument, however, leads to the hypothesis that enhancers of the Xenopus type are widespread among both plants and animals. As we have pointed out previously (Reeder 1985), nucleolar dominance between $X$. laevis and $X$. borealis can be most readily explained as the result of competition due to the unequal numbers of enhancers in the spacers of the two species. Examples of nucleolar dominance, with the cytological characteristics of the Xenopus crosses, have been widely reported in plants, insects, and even in mammals. If the enhancer imbalance model advanced for nucleolar dominance in Xenopus is correct, then repetitive enhancer elements might be very widespread among plants and animals. Our discovery that the Xenopus enhancer binding protein $\mathrm{xUBF}$ is a transcription factor with closely related counterparts in mammalian species lends credence to this hypothesis.

\section{Methods}

\section{Preparation of extract}

$X$. laevis kidney cells (line A6) were grown at room temperature in roller bottles in $50 \%$ L-15 media (Flow Laboratories), supplemented with $5 \%$ fetal calf serum (GIBCO), $5 \%$ NuSerum (Collaborative Research), $2 \mathrm{~mm}$ glutamine (GIBCO), and 100 units each of penicillin and streptomycin (GIBCO). Cells were harvested at late $\log$ phase by scraping and then were pelleted, washed once with PBS, and pelleted again. Typically, $6 \mathrm{ml}$ of packed cells was obtained from 10 roller bottles.

Nuclei were prepared by a modification of the method of Crampton and Woodland (1978). All solutions were chilled to $4^{\circ} \mathrm{C}$, and work was performed on ice in the cold room. Cell pellets $(\sim 6 \mathrm{ml})$ were resuspended in $40 \mathrm{ml}$ of homogenization buffer: $10 \mathrm{~mm}$ Tris ( $\mathrm{pH} 8.0$ ), $0.3 \mathrm{M}$ sucrose, $3 \mathrm{mM} \mathrm{CaCl}_{2}, 2 \mathrm{~mm}$ magnesium acetate, $0.1 \%$ NP-40, 0.1\% Triton X-100, $0.5 \mathrm{~mm}$, DTT, $0.1 \mathrm{mM}$ PMSF, $1 \mathrm{~mm}$ sodium metabisulfite (Aldrich), and $2 \mu \mathrm{g} / \mathrm{ml}$ aprotinin (Sigma). Resuspended cells were homogenized with $\sim 40$ strokes of an A pestle in a $40-\mathrm{ml}$ Wheaton homogenizer and checked microscopically for cell lysis. An equal volume of centrifugation buffer was added $[10 \mathrm{~mm}$ Tris $(\mathrm{pH} 8.0)$, $1.85 \mathrm{M}$ sucrose, $5 \mathrm{~mm}$ magnesium acetate, $0.5 \mathrm{~mm}$ DTT, $0.1 \mathrm{mM}$ PMSF, $1 \mathrm{mM}$ sodium metabisulfite, $2 \mu \mathrm{g} / \mathrm{ml}$ aprotinin $]$, and 30 $\mathrm{ml}$ of the cell lysate was layered over a $6-\mathrm{ml}$ cushion of centrifugation buffer in $36-\mathrm{ml}$ ultracentrifuge tubes. Nuclei were pelleted by centifugation at $64,000 \mathrm{~g}$ in a swinging bucket rotor for $45 \mathrm{~min}$ at $40^{\circ} \mathrm{C}$. Tubes were drained by inversion, and the six pellets were resuspended by gentle homogenization in a $15-\mathrm{ml}$ Wheaton homogenizer in a total of $10 \mathrm{ml}$ of nuclear extraction buffer [20 mM HEPES (pH 7.9), 25\% glycerol, $0.4 \mathrm{M} \mathrm{KCl}, 1.5 \mathrm{~mm}$ $\mathrm{MgCl}_{2}, 0.2 \mathrm{~mm}$ EDTA, $1 \mathrm{~mm}$ DTT, $1 \mathrm{~mm}$ PMSF, $0.1 \mathrm{~mm}$ sodium metabisulfite], similar to that described by Dignam et al. 
(1983). Nuclei were extracted on ice for $\sim 30 \mathrm{~min}$ and then centrifuged in a $15-\mathrm{ml}$ corex tube at $10,000 \mathrm{~g}$ for $10 \mathrm{~min}$ to pellet nuclei. The supernatant was dialyzed for $4-5 \mathrm{hr}$ against 50 volumes of $0.1 \mathrm{M} \mathrm{KCl}$ column buffer (CB100): 25 mM HEPES (pH 7.9), 20\% glycerol, $0.1 \mathrm{M} \mathrm{KCl,} 0.1 \mathrm{~mm}$ EDTA, $1 \mathrm{~mm}$ DTT, $0.1 \mathrm{mM}$ PMSF, and $0.1 \mathrm{~mm}$ sodium metabisulfite. After dialysis, the extract was centrifuged again at $10,000 \mathrm{~g}$ for $10 \mathrm{~min}$ to remove insoluble material and stored frozen at $-70^{\circ} \mathrm{C}$.

\section{Purification of $x U B F$}

Approximately $125 \mathrm{mg}$ of nuclear protein from $\sim 40 \mathrm{ml}$ of packed cells was loaded onto an 18-ml DEAE-Sepharose column equilibrated in CB100. The column was washed with CB100 until protein levels returned to baseline and then was eluted sequentially with $0.23 \mathrm{M} \mathrm{KCl}$ column buffer (CB230) and $\mathrm{CB} 340$. The protein eluting at $0.34 \mathrm{M} \mathrm{KCl}(14.8 \mathrm{mg}$ ) was applied directly to a $2-\mathrm{ml}$ Bio-Rex-70 column equilibrated in CB340, which was then washed until flowthrough protein levels returned to baseline. xUBF was then eluted with $0.8 \mathrm{M} \mathrm{KCl}$ buffer (in $1.5 \mathrm{mg}$ total protein), dialyzed overnight against column buffer containing $50 \%$ glycerol and $0.2 \mathrm{M} \mathrm{KCl}$, and stored at $-20^{\circ} \mathrm{C}$.

A DNA affinity column was made from polymerized 60-bp double-stranded oligodeoxynucleotides representing the 56-bp minimal enhancer (see EM0; Pikaard and Reeder 1988), coupled to CNBr-activated Sepharose (Kadonaga and Tjian 1986). The sequence of the two oligodeoxynucleotides was 5'TCGACAGCCC CACCGGGAGT TCCAGGAGCT CGGGCAGGGG GAGCAGGCTC GTCCCCCTGC-3' and 5'-TCGAGCAGGG GGACGAGCCT GCTCCCCCTG CCCGAGCTCC TGGAACTCCC GGTGGGGCTG-3'.

Bio-Rex-purified xUBF was adjusted to $0.1 \mathrm{M} \mathrm{KCl}, 20 \%$ glycerol, in column buffer, mixed with $50 \mu \mathrm{g}$ of poly[d(A-T)], and stored on ice for $15 \mathrm{~min}$. The protein was applied to a $0.8-\mathrm{ml}$ affinity column, and the flowthrough reapplied twice. The column was washed with 4 column volumes of CB200 and was eluted with 1.5 volumes CB600. For the second round of affinity purification, first-round material was diluted to $0.2 \mathrm{M}$ $\mathrm{KCl}$ and applied to a $0.3-\mathrm{ml}$ column, which then was washed as before and eluted with CB400, CB600, and CB800. The peak of xUBF activity eluted in CB600. An aliquot of the protein was saved for SDS-polyacrylamide gel electrophoresis (PAGE); the remainder was adjusted to $1 \mathrm{mg} / \mathrm{ml}$ BSA (Boehringer-Mannheim) and dialyzed into $50 \%$ glycerol CB200 and stored at $-20^{\circ} \mathrm{C}$. The final yield of xUBF starting from $40 \mathrm{ml}$ of packed cells was $\sim 5 \mu \mathrm{g}$.

\section{Protein analysis}

SDS-PAGE was performed as described by Laemmli (1970) in $10 \%$ acrylamide minigels (Bio-Rad) that were silver-stained according to the manufacturer's directions. Protein estimations were performed by the method of Bradford (1976) (Bio-Rad), using BSA as the standard.

\section{Renaturation of $\mathrm{x} U B F$}

Renaturation was performed by the method of Hager and Burgess (1980), except that buffers contained $\mathrm{KCl}$ instead of $\mathrm{NaCl}$. Approximately $1 \mu \mathrm{g}$ of affinity-purified $\mathrm{xUBF}$ was run on one lane of a $10 \%$ SDS-polyacrylamide gel, which was then cut into five slices. Proteins were eluted from the SDS-gel slices and precipitated with 5 volumes of acetone. The pellets were resuspended in $20 \mu \mathrm{l}$ of buffer containing $6 \mathrm{M}$ guanidine- $\mathrm{HCl}$, diluted to $1 \mathrm{ml}$, and allowed to renature. After overnight incu- bation, the protein was concentrated to a volume of $60-100 \mu \mathrm{l}$ by ultrafiltration in Centicon 10 (Amicon) microconcentrators and tested for footprinting activity.

\section{Footprinting and probes}

DNase I footprinting (Galas and Schmitz 1978) was performed as described by Walker and Reeder (1988), except that nonspecific competitor DNA was not necessary in the protein-DNAbinding reaction. Probes were 5 '-end-labeled with T4 kinase and purified on $5 \%$ polyacrylamide gels. Xenopus promoter probes were the SalI $(-245) / B a m H I(+50)$ fragment of the minigene $\Psi 40$ (or the same fragment from EcoRI LS mutants of $\Psi 40)$ or the $X b a \mathrm{I}(-167) / B a m H I(+50)$ fragment of the 'zero bp push-apart' mutant described by McStay and Reeder (1986). The enhancer probe was a PstI fragment from the enhancer block of pXlrl4F (Botchan et al. 1977), subcloned into a Bluescribe vector and digested with EcoRI and HindIII. This probe has one 60- and one 81-bp enhancer repeat arranged head to tail. The T3 probe was the SalI $(-245) / S m a I(-166)$ fragment of $\Psi 40$. The human promoter probe was the HincII $(-170) /$ BstEII $(+80)$ fragment.

\section{In vitro transcription}

S-100 extracts from cultured $X$. laevis kidney cells and in vitro transcription reactions were performed essentially according to McStay and Reeder (1986). Reactions were as follows: $20 \mu \mathrm{l}$ of S-100 extract and $200 \mathrm{ng}$ of pBR322 (in $1 \mu \mathrm{l}$ ) were mixed and incubated on ice for $10 \mathrm{~min} ; 25 \mu \mathrm{l}$ of $2 \times$ reaction mix [15 mM HEPES (pH 7.9), $60 \mathrm{~mm} \mathrm{KCl,} 10 \mathrm{~mm} \mathrm{MgCl}_{2}, 1 \mathrm{~mm}$ DTT, $200 \mu \mathrm{g}$ $\alpha$-amanitin, $1 \mathrm{~mm}$ each ATP, CTP, GTP, UTP] was added followed by either $2 \mu l$ of xUBF buffer $(50 \%$ glycerol CB200) or 2 $\mu \mathrm{l}$ of affinity-purified xUBF $(\sim 30 \mathrm{ng})$. Competitor DNA was added in a volume of $1 \mu \mathrm{l}$, using either pGEM3 or pXlr14FA-8, a pGEM3 vector containing eight enhancer blocks (each block has 10 intermixed 60- and 81-bp enhancers) derived from the parent clone pXlr14FA [for sequence of pXlr14FA, see Pikaard and Reeder (1988)]. Reactions were started by the addition of $100 \mathrm{ng} \Psi 40$ (in $1 \mu \mathrm{l}$ ), and were incubated for $2 \mathrm{hr}$ at $25^{\circ} \mathrm{C}$. RNA was then purified by phenol/chloroform extraction followed by ethanol precipitation. Transcription was assayed by nuclease S1 protection, using the 295-bp SalI/BamHI fragment of $\Psi 40$ labeled at the BamHI site (Labhart and Reeder 1986).

An oocyte nuclear extract was prepared from nuclei manually isolated under paraffin oil (M. Schultz, in prep.). Isolated nuclei were disrupted gently at $4^{\circ} \mathrm{C}$ in $4 \mu \mathrm{l}$ of homogenization buffer [10 mM HEPES (pH 7.9), $50 \mathrm{mM} \mathrm{KCl}, 3 \mathrm{mM} \mathrm{MgCl} 2,2.5$ mM DTT, 0.05 mM EDTA, 2.5\% glycerol, $40 \mathrm{~mm}$ phosphocreatine, $100 \mu \mathrm{g} / \mathrm{ml}$ creatine phosphokinase, $200 \mu \mathrm{g} / \mathrm{ml} \alpha$-amanitin] per five nuclei. The homogenate was spun immediately at $10,500 \mathrm{~g}$ for $15 \mathrm{sec}$ in a microfuge to remove large particles. The resultant low-speed supernatant was the transcription extract. This low-speed supernatant was fractionated by centrifugation at $10,500 \mathrm{~g}$ for $10 \mathrm{~min}$. The $10,500 \mathrm{~g}$ pellet was resuspended in 4 $\mu l$ of dilution buffer (homogenization buffer minus phosphocreatine, creatine phosphokinase, and $\alpha$-amanitin). Transcription reactions shown in Figure 8 contained either $4 \mu$ lof lowspeed supernatant, $4 \mu \mathrm{l}$ of $10,500 \mathrm{~g}$ supernatant, $4 \mu \mathrm{l}$ of $10,500 \mathrm{~g}$ pellet, a mixture of $4 \mu \mathrm{l}$ each of $10,500 \mathrm{~g}$ pellet and supernatant, or $4 \mu \mathrm{l}$ of $10,500 \mathrm{~g}$ supernatant plus $4 \mu \mathrm{l}$ of affinity-purified xUBF $(\sim 30 \mathrm{ng})$ that had been dialyzed against dilution buffer. Where necessary, the final volume was brought to $8 \mu \mathrm{l}$ by the addition of dilution buffer. One microliter of template/nucleotide mix (2.5 ng template, $800 \mu \mathrm{M}$ each ATP, CTP, GTP, UTP in homogenization buffer amended to contain $20 \mathrm{mM}$ phospho- 
creatine, $50 \mu \mathrm{g} / \mathrm{ml}$ creatine phosphokinase, $100 \mu \mathrm{g} / \mathrm{ml} \alpha$-amanitin) was added, and the reactions were incubated at $25^{\circ} \mathrm{C}$ for 4 hr. RNA purification and S1 analysis were performed as described above.

\section{Acknowledgments}

We thank R. Tjian for comments on the manuscript and for exchanging unpublished data. J. Roan provided excellent technical assistance.

\section{References}

Bell, S.P., R.M. Learned, H.-M. Jantzen, and R. Tjian. 1988. Functional cooperativity between transcription factors UBF1 and SL1 mediates human ribosomal RNA transcription. Science 241: 1192-1197.

Bell, S.P., C.S. Pikaard, R.H. Reeder, and R. Tjian. 1989. Molecular mechanisms governing species specific transcription of ribosomal RNA. Cell (in press).

Botchan, P., R.H. Reeder, and I.B. Dawid. 1977. Restriction analysis of the non-transcribed spacer of Xenopus laevis ribosomal DNA. Cell 11: 599-607.

Bradford, M.M. 1976. A rapid and sensitive method for the quantitation of microgram quantities of protein utilizing the principle of protein-dye binding. Anal. Biochem. 72: 248254.

Busby, S.J. and R.H. Reeder. 1983. Spacer sequences regulate transcription of ribosomal gene plasmids injected into Xenopus embryos. Cell 34: 989-996.

Crampton, J.M. and H.R. Woodland. 1978. A cell-free assay system for the analysis of changes in RNA synthesis during the development of Xenopus laevis. Dev. Biol. 70: 453-466.

DeWinter, R.J.F. and T. Moss. 1987. A complex array of sequences enhances ribosomal transcription in Xenopus laevis. J. Mol. Biol. 196: 813-827.

Dignam, J.D., R.M. Lebovitz, and R.G. Roeder. 1983. Accurate transcription initiation by RNA polymerase II in a soluble extract from isolated mammalian nuclei. Nucleic Acids Res. 11: $1475-1489$.

Galas, D. and A. Schmitz. 1978. DNase footprinting: A simple method for the detection of protein-DNA binding specificity. Nucleic Acids Res. 5: 3157-3170.

Grimaldi, G. and P.P. Di Nocera. 1988. Multiple repeated units in Drosophila melanogaster ribosomal DNA spacer stimulate rRNA precursor transcription. Proc. Natl. Acad. Sci. 85: 5502-5506.

Grummt, I., E. Roth, and M.R. Paule. 1982. rRNA transcription in vitro is species specific. Nature 296: 173-174.

Hager, D.A. and R.R. Burgess. 1980. Elution of proteins from sodium dodecyl sulfate-polyacrylamide gels, removal of sodium dodecyl sulfate, and renaturation of enzymatic activity: Results with sigma subunit of Escherichia coli RNA polymerase, wheat germ DNA topoisomerase, and other enzymes. Anal. Biochem. 109: 76-86.

Kadonaga, J.T. and R. Tiian. 1986. Affinity purification of sequence-specific DNA binding proteins. Proc. Natl. Acad. Sci. 83: 5889-5893.

Labhart, P. and R.H. Reeder. 1984. Enhancer-like properties of the $60 / 81 \mathrm{bp}$ elements in the ribosomal gene spacer of Xenopus laevis. Cell 37: 285-289.

- 1986. Characterization of three sites of 3 ' end formation in the Xenopus ribosomal gene spacer. Cell 45: 431-443.

- 1987. A 12-base-pair sequence is an essential element of the ribosomal gene terminator in Xenopus laevis. Mol. Cell. Biol. 7: 1900-1905.
Laemmli, U.K. 1970. Cleavage of structural proteins during the assembly of the head of bacteriophage T4. Nature 227: 680685.

Learned, R.M. and R. Tjian. 1982. In vitro transcription of human rRNA genes by RNA polymerase I. I. Mol. Appl. Genet. 1: 575-584.

McStay, B. and R.H. Reeder. 1986. A termination site for Xenopus RNA polymerase I also acts as an element of an adjacent promoter. Cell 47: 913-920.

Miesfeld, R. and N. Arnheim. 1984. Species-specific rDNA transcription is due to promoter-specific binding factors. Mol. Cell. Biol. 4: 221-227.

Mishima, Y., I. Financsek, R. Kominami, and M. Muramatsu. 1982. Fractionation and reconstitution of factors required for accurate transcription of mammalian ribosomal RNA genes: Identification of a species-dependent initiation factor. Nucleic Acids Res. 10: 6659-6670.

Moss, T. 1983. A transcriptional function for the repetitive ribosomal spacer in Xenopus laevis. Nature 302: 223-228.

Pfeifer, K., T. Prezant, and L. Guarente. 1987. Yeast HAP1 activator binds to two upstream activation sites of different sequence. Cell 49: 19-27.

Pikaard, C.S. and R.H. Reeder. 1988. Sequence elements essential for function of the Xenopus laevis ribosomal DNA en hancers. Mol. Cell. Biol. 8: 4282-4288.

Reeder, R.H. 1984. Enhancers and ribosomal gene spacers. Cell 38: $349-351$.

- 1985. Mechanisms of nucleolar dominance in animals and plants. I. Cell Biol. 101: 2013-2016.

Reeder, R.H., D. Pennock, B. McStay, J. Roan, E. Tolentino, and P. Walker. 1987. Linker scanner mutagenesis of the Xenopus laevis ribosomal gene promoter. Nucleic Acids Res. 15: 7429-7441.

Walker, P. and R.H. Reeder. 1988. The Xenopus laevis ribosomal gene promoter contains a binding site for Nuclear Factor-1. Nucleic Acids Res. 16: 10657-10668.

Wilkinson, J.K. and B. Sollner-Webb. 1982. Transcription of Xenopus ribosomal RNA genes by RNA polymerase I in vitro. J. Biol. Chem. 257: 14375-14383. 


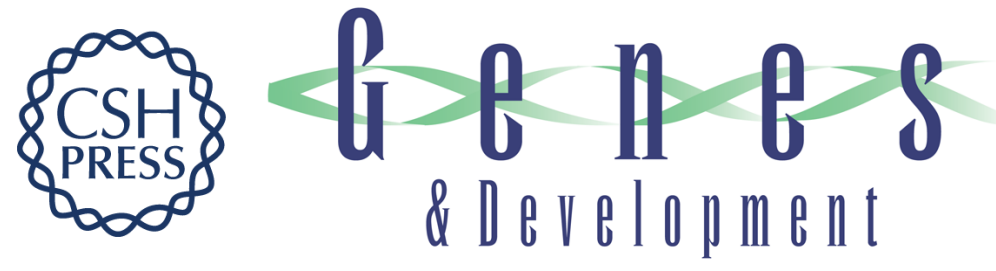

\section{The Xenopus ribosomal gene enhancers bind an essential polymerase I transcription factor, XUBF.}

C S Pikaard, B McStay, M C Schultz, et al.

Genes Dev. 1989, 3:

Access the most recent version at doi:10.1101/gad.3.11.1779

References This article cites 28 articles, 8 of which can be accessed free at:

http://genesdev.cshlp.org/content/3/11/1779.full.html\#ref-list-1

License

Email Alerting

Service

Receive free email alerts when new articles cite this article - sign up in the box at the top right corner of the article or click here.

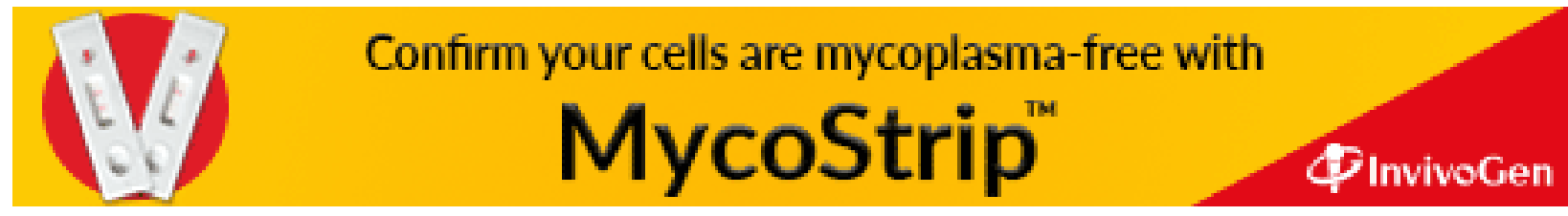

